\title{
Sedation after spinal anesthesia in elderly patients: a preliminary observational study with the PSA-4000
}

\author{
[La sédation après une rachianesthésie chez des patients âgés : une étude observa- \\ tionnelle préliminaire avec le PSA-4000]
}

Viji Kurup MD, Ramachandran Ramani MD, Peter G. Atanassoff MD

Purpose: Neuraxial blockade is known to have a sedative effect, decreasing the need for inhalational and iv anesthetic agents. The purpose of the present study was to quantify the sedative effect of spinal anesthesia and to determine the time of maximum sedation.

Methods: This is an observational study in which 20 unsedated patients were scheduled to undergo urologic and orthopedic surgeries under spinal anesthesia. Patients with pre-existing neurological conditions or receiving psychotropic medications were excluded from the study. All received I.5 mL ( I I.25 mg) of hyperbaric bupivacaine $0.75 \%$ intrathecally. No sedative or narcotic was administered intravenously or intrathecally. The Patient State Analyzer, (PSA-4000) was used to monitor sedation along with Observer's Assessment of Alertness and Sedation (OAA/S) scores every five minutes. Differences in patient state index (PSI) and OAA/S scores are expressed as median and range and were evaluated by Wilcoxon's signed rank test for non-parametric data; $P<0.05$ was considered significant. PSI, OAA/S and time at lowest score are expressed as median(range).

Results: PSI scores decreased from baseline 99 (96-99) to 78 (56-87) at 35(|4.5-54) min into the spinal anesthetic $(P<0.05)$. $\mathrm{OAA} / \mathrm{S}$ scores decreased from baseline 5 to 4 (range $3-5$ ) at the time of the lowest PSI scores $(P<0.05)$.

Conclusions: In this elderly patient population, spinal anesthesia induced changes in the processed electroencephalogram with reduction in PSI and OAA/S scores. The reduction in afferent input to the reticular activating system could possibly explain the sedation that has been observed and the reduction in the PSA scores.
Objectif : L'effet sédatif du bloc neuraxial est connu pour diminuer les besoins d'anesthésiques iv et par inhalation. Nous avons voulu quantifier l'effet sédatif de la rachianesthésie et déterminer le temps nécessaire pour atteindre la sédation maximale.

Méthode : L'étude observationnelle porte sur 20 patients sans sédation qui doivent subir une intervention sous rachianesthésie en chirurgie urologique ou orthopédique. Sont exclus ceux qui ont des pathologies neurologiques préexistantes ou un traitement psychotrope. Tous reçoivent 1,5 mL ( I I,25 mg) de bupivacaïne hyperbare à 0,75 \% par voie intrathécale. Aucun sédatif ou narcotique n'est administré par voie intraveineuse ou intrathécale. Le Patient State Analyzer, (PSA4000), un analyseur de l'état du patient, est utilisé pour surveiller la sédation au même titre que l'Observer's Assessment of Alertness and Sedation (OAA/S) scores (évaluation de la vigilance et de la sédation par un observateur) toutes les cinq minutes. Les différences de l'index de l'état du patient (IEP) et les scores de l'OAA/S sont exprimés par la médiane et les valeurs extrêmes et évalués par le test de rang des signes de Wilcoxon pour les données non paramétriques; $P<0,05$ est considéré significatif. L'IEP, l'OAA/S et le moment du score le plus bas sont exprimés par la médiane (valeurs extrêmes).

Résultats : Les scores de l'IEP ont baissé, par rapport aux données du début, de 99 (96-99) à 78 (56-87) à 35(14,5-54) min avec la rachianesthésie $(P<0,05)$. Les scores à l'OAA/S ont été plus bas que les données initiales, passant de 5 à 4 (3-5) au moment des scores IEP les plus bas $(P<0,05)$.

Conclusion : Chez les patients âgés, la rachianesthésie a induit des changements à l'électroencéphalogramme traité et une réduction des scores de l'IEP et de l'OAA/S. La réduction des afférences au système réticulé activateur peut expliquer la sédation observée et la réduction des scores du PSA.

From the Department of Anesthesiology, Yale University School of Medicine, New Haven, Connecticut, USA. Address correspondence to: Dr. Viji Kurup, Yale University School of Medicine, Department of Anesthesiology, 333 Cedar Street, P.O.

Box 208051, New Haven, CT 06520-8051, USA. Phone: 203-785-2802; Fax: 203-785-6664; E-mail: viji_kurup@comcast.net

Disclosure: We did not receive any funding from any source and have no commercial affiliation with the product manufacturers. Accepted for publication October 15, 2003.

Revision accepted March 24, 2004. 


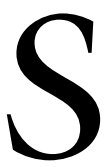

PINAL anesthesia with local anesthetics alone has been known to have a sedative effect. ${ }^{1} \mathrm{~A}$ number of studies ${ }^{2-4}$ show a decrease in the dose of inhalational anesthetic agents as well as iv sedative/hypnotics needed to ablate responses to nociceptive stimuli when the patient has received neuraxial blockade. It has been postulated that the reason for this phenomenon is decreased sensory input to the reticular activating system (RAS) as a result of the profound sensory blockade. ${ }^{2,5}$ Gentili postulated that the loss of proprioceptive inputs from muscles and joints during a spinal block may also contribute to the increased sensitivity to anesthetic agents. ${ }^{6}$ The literature available at this point is not conclusive as to the effect of spinal anesthesia on the electroencephalogram (EEG). Pollock ${ }^{7}$ observed that spinal anesthesia was accompanied by sedation with significant changes in bispectral index (BIS) scores in the first part of the study involving 12 volunteers. However BIS was not seen to be a sensitive measure of the sedation associated with spinal anesthesia in the second randomized blinded portion of the study. In the present study, a new device - the Patient State Analyzer (PSA-4000, Baxter/Physiometrix Inc., N. Billerica, MA, USA) - which displays a four-channel EEG and patient state index (PSI), was used. The PSI score displayed by the PSA monitor is based on discriminant analysis of a multivariate combination of quantitative EEG variables. ${ }^{8}$ Considering that PSI is derived from a four-channel EEG it is anticipated that the data would be a sensitive reflector of global EEG activity. The present investigation aimed to quantify the sedative effect of spinal anesthesia and to gain some insight into the time of maximum sedation by looking at processed EEG using the PSA in elderly patients.

\section{Methods}

The study protocol was approved by the Human Investigations Committee of Yale University School of Medicine. The study population included 20 patients, ASA I or II, scheduled to undergo urologic or orthopedic procedures. Verbal informed consent was obtained from each patient after discussion of the anesthetic and monitoring plan. Exclusion criteria were pre-existing neurological conditions, patient refusal, patients on psychotropic medications or coagulation disorders.

A peripheral $i v$ catheter was inserted on arrival of the patient in the operating room and a balanced salt solution was administered. Monitoring consisted of a two-lead electrocardiogram (II and V5), non-invasive blood pressure and pulse oximetry.

The PSA-4000 was used for obtaining the EEG and displaying the PSI values. A disposable patient dedicated electrode set (PSArray) was applied to the patient's scalp. The PSA module and PSArray are shown in the Figure. It consists of seven pre-gelled leads- one ground (FP2), four sensing electrodes and two referenced electrodes over the mastoids in a fixed arrangement. The electrodes span the bilateral frontalpolar regions and the midline locations, including $\mathrm{FPZ}^{1} \mathrm{FPz}, \mathrm{Cz}$ and $\mathrm{Pz}$, as defined by the international $10 / 20$ electrode placement system.

Baseline recordings from all monitors were obtained for a period of three minutes. The patient was then turned into the lateral decubitus position and spinal anesthesia was administered with $11.25 \mathrm{mg}$ of hyperbaric bupivacaine $0.75 \%$. The patient was then turned supine and PSI readings were recorded continuously. Patients did not take any medications preoperatively that might have impacted PSI readings nor were they given any sedatives or narcotics either intrathecally or intravenously throughout the procedure. The responsiveness component of the Observer's Assessment of Alertness/Sedation (OAA/S) score ${ }^{9}$ was also recorded every five minutes [5- Responds readily to name spoken in normal tone; 4- Lethargic response to name spoken in normal tone; 3- Responds only after name is called loudly and/or repeatedly, or lash reflex is present; 2Loss of lash reflex, or has a positive response to train-offour (TOF) stimulation (i.e., opens eyes); 1- No purposeful response to TOF stimulation].

Data for times of surgical procedures and duration of spinal anesthesia were normally distributed and are expressed as mean \pm SD. The baseline and lowest PSI scores as well as OAA/S scores are expressed as median (range) and were evaluated by Wilcoxon's signed rank test for non-parametric data; $P<0.05$ was considered significant.

\section{Results}

All patients had successful spinal anesthesia and did not require any additional analgesic or sedative drugs. Patients enrolled in the study were $70 \pm 15 \mathrm{yr}$ of age, weighed $77 \pm 20 \mathrm{~kg}$ and $55 \%$ of the subjects were males. Surgical procedures lasted $66 \pm 35 \mathrm{~min}$, the observation period for the spinal anesthetic was $88 \pm$ $36 \mathrm{~min}$. PSI scores decreased from baseline 99 (range 96-99) to a nadir of 78 (range $56-87 ; P<0.05$ ). The time of maximum sedation was $34 \pm 16$ min (mean \pm $\mathrm{SD}$ ) into the spinal anesthetic. OAA/S decreased from 5 at baseline to 4 (range 3-5) at the time of the lowest PSI scores $(P<0.05)$. Following spinal anesthesia to a dermatomal level of $\mathrm{T} 8 \pm 2$, the mean arterial pressure decreased from baseline (mean \pm SD) $103 \pm$ $12 \mathrm{mmHg}$ to $76 \pm 11 \mathrm{mmHg}$ at the time of the lowest PSI score $(P<0.05)$. 

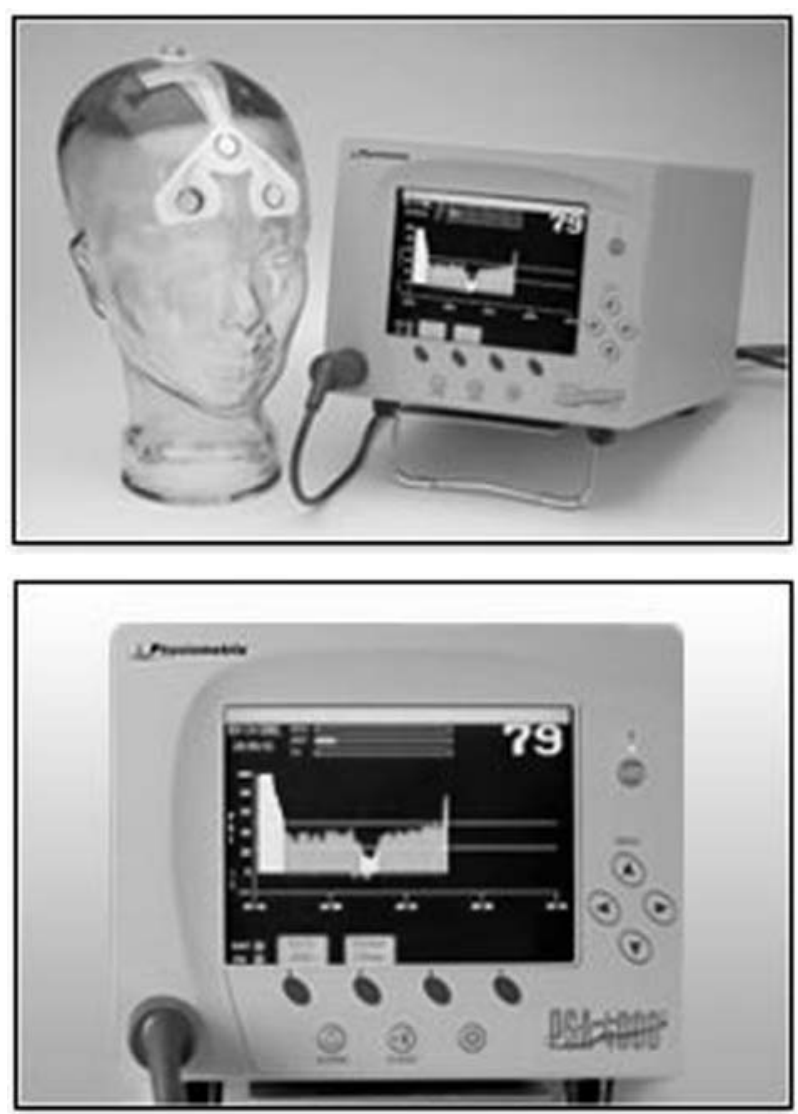

FIGURE The PSA module and the PSArray (pictures reproduced with permission from Physiometrix Inc., N. Billerica, MA, USA).

Spearman correlation between PSI and OAA $/ S$ was performed showing modest correlation between baseline PSI and OAA $/ S$ with $r=0.591$, delta PSI and delta OAA $/ \mathrm{S}(\mathrm{r}=0.527)$ and lowest PSI and OAA $/ \mathrm{S}$ $(\mathrm{r}=0.50)$.

\section{Discussion}

In this elderly unsedated patient population, spinal anesthesia with local anesthetic alone induced changes in the processed EEG with reduction in PSI scores along with a significant decrease in OAA/S scores.

Patients undergoing spinal anesthesia frequently demonstrate drowsiness although they have not received any sedative drugs. ${ }^{1}$ Animal experiments in the 1960s showed that spinal cord section or its cooling at the $\mathrm{Tl}$ level resulted in behavioural and electrophysiological evidence of sleep and showed an electrocortical sleep pattern. ${ }^{10}$ Spinal anesthesia decreases the activity of the RAS and this causes sedation. RAS being a polysynaptic pathway, is much more susceptible to suppression than axons. ${ }^{11}$ It has been speculated that the reason for this phenomenon is related to a decrease in the tonic sensory and musclespindle activity, which maintains a state of wakefulness. ${ }^{6}$ In addition, it was proposed that decreased afferent input to the brain could lessen excitatory descending modulation of spinal cord motor neurons and suppress motor function leading to the observed decrease in requirement of inhalational anesthetic agents in patients receiving neuraxial blockade and general anesthesia. Lower doses of sedatives and hypnotics such as midazolam, ${ }^{2}$ thiopental ${ }^{2,3}$ and propo$\mathrm{fol}^{12}$ are needed to induce hypnosis after intrathecal or epidural blockade, implying a sedative effect of neuraxial anesthesia.

The degree of sedation resulting from a spinal anesthetic may have important clinical implications. Caplan ${ }^{13}$ in his closed claims study of major anesthetic mishaps during spinal anesthesia indicated that adverse events often occurred in patients who were sedated beyond the ability to respond to verbal command. They also indicated that the overall doses of sedatives used were well within the customary limits. It is possible that standard doses of sedative drugs may have an exaggerated effect in patients under spinal anesthesia. Pollard ${ }^{14}$ suggests that since sedation is used in more than $80 \%$ of patients who undergo spinal anesthesia, the potential role of sedation in the occurrence of cardiac arrests during spinal anesthesia must be considered.

However, the sedation patients achieve under spinal anesthesia has not been quantified, nor have any clear ideas regarding the time of maximum sedation been put forth. The present investigation was performed to answer these questions using processed EEG by means of a comparatively new device along with the OAA/S scale to measure the degree of sedation after spinal anesthesia. Various methods of analyzing the EEG intraoperatively are available. The BIS monitor is specifically designed to assess the depth of sedation under general anesthesia. BIS technology assumes that for quantifying sedation, frontal lobe EEG would reflect global EEG activity. In contrast, the PSA is based on four-channel EEG. EEG epochs of $1.25 \mathrm{sec}$ are frequency transformed, and power in the various frequency ranges is calculated. The scores range from 0 to 100 with decreasing scores indicating increased levels of sedation/hypnosis. Prichep ${ }^{15}$ found the PSI scores to be significantly related to the state of hypnosis of the patient as measured by standard scales of measurement of sedation for total iv anesthesia, 
inhalation anesthetics (isoflurane, sevoflurane and desflurane) and nitrous/narcotic anesthesia. Subsequent studies ${ }^{16}$ found the PSI to have a significant relation to the level of hypnosis under propofol, alfentanil, and nitrous oxide anesthesia. The sensitivity of this measurement is also due to the use of neurometrics, which takes into account differences in individual background EEGs as well as individual variability of the brain's response to anesthetic agents thus decreasing the variance within each individual patient. Because of the sophisticated quantification of EEG and global monitoring of the EEG activity, it is anticipated that this technique would enhance the sensitivity and specificity of measurement of depth of consciousness. The reason Pollock ${ }^{7}$ observed no change in BIS, could be related to the lack of sensitivity of the BIS monitor for this level of sedation. The PSA monitor with its new technology seems to be a more sensitive monitor for measuring small changes in the level of consciousness as would be expected in a setting of unsedated patients and hence was chosen for this study.

We acknowledge some drawbacks of this study. This is an observational study and no control group was used. Patients were studied for $88 \pm 36 \mathrm{~min}$. In patients who were observed for more than $60 \mathrm{~min}$ we did not notice an increase in sedation at $65 \mathrm{~min}$ as was observed by Pollock. ${ }^{7}$ It remains to be seen if these results can be duplicated in a randomized, blinded placebo-controlled trial.

\section{Conclusion}

Spinal anesthesia with bupivacaine $0.75 \%$ in an elderly population produced a statistically significant decrease in sedation scores as evidenced by the PSA-4000. The peak effect was seen approximately $35 \mathrm{~min}$ into the spinal anesthetic. This was accompanied by a statistically significant decrease in OAA/S scores. Most likely, a decrease in afferent sensory input to the RAS contributed to the sedative effect after spinal anesthesia. However further clinical experience with this new monitor is necessary to establish whether this will translate into a titrated administration of sedatives during a neuraxial blockade.

\section{References}

1 Greene NM, Brull SJ. Physiology of Spinal Anesthesia, 4th edition. Baltimore: Williams and Wilkins; 1993: 65-7.

2 Tverskoy M, Shagal M, Finger J, Kissin I. Subarachnoid bupivacaine blockade decreases midazolam and thiopental hypnotic requirements. J Clin Anesth 1994; 6: 487-90.

3 Eappen S, Kissin I. Effect of subarachnoid bupivacaine block on anesthetic requirements for thiopental in rats. Anesthesiology 1998; 88: 1036-42.

4 Hodgson PS, Liu SS, Gras TW. Does epidural anesthesia have general anesthetic effects? Anesthesiology 1999; 91: 1687-92.

5 Ben-David B, Vaida S, Gaitini L. The influence of high spinal anesthesia on sensitivity to midazolam sedation. Anesth Analg 1995; 81: 525-8.

6 Gentili M, Huu PC, Enel D, Hollande J, Bonnet F. Sedation depends on the level of sensory block induced by spinal anaesthesia. Br J Anaesth 1998; 81: 970-1.

7 Pollock JE, Neal JM, Liu SS, Burkhead D, Polissar N. Sedation during spinal anesthesia. Anesthesiology 2000; 93: 728-34.

8 Drover DR, Lemmens HJ, Pierce ET, et al. Patient state index. Titration of delivery and recovery from propofol, alfentanil, and nitrous oxide anesthesia.

Anesthesiology 2002; 97: 82-9.

9 Chernik DA, Gillings D, Laine $H$, et al. Validity and reliability of the observer's assessment of alertness/sedation scale: study with intravenous midazolam. J Clin Psychopharmacol 1990; 10: 244-51.

10 Oreshchuk FA. The development of sleep on local cooling of the spinal cord. Fiziol Z (Moscow). 1960; 46: 1230-5.

11 Larrabee MG, Posternak JM. Selective action of anesthetics on synapses and axons in mammalian sympathetic ganglion. J Neurophysiol 1952; 15: 91.

12 Tverskoy M, Fleyshman G, Bachrak L, Ben-Shlomo I. Effect of bupivacaine-induced spinal block on the hypnotic requirement of propofol. Anaesthesia 1996; 51: 652-3.

13 Caplan RA, Ward RJ, Posner K, Cheney FW. Unexpected cardiac arrest during spinal anesthesia: a closed claims analysis of predisposing factors. Anesthesiology 1988; 68: 5-11.

14 Pollard JB. Cardiac arrest during spinal anesthesia: common mechanisms and strategies for prevention. Anesth Analg 2001; 92: 252-6.

15 Prichep LS, John ER, Gugino LD, Kox W, Chabot RJ. Quantitative EEG assessment of changes in the level of sedation/hypnosis during surgery under general anesthesia. In: Jordon C, Vaughan DJ, Newton DE (Eds). Memory and Awareness in Anaesthesia IV. World Scientific Publishing Co.; 1998: 97-107.

16 Billard V, Gambus PL, Chamoun N, Stanski DR, Shafer $S L$. A comparison of spectral edge, delta power, and bispectral index as EEG measures of alfentanil, propofol, and midazolam drug effects. Clin Pharmacol Therap 1997; 61: 45-58. 